ORIGINAL ARTICLE

\title{
Multiple meningiomas: differential involvement of the NF2 gene in children and adults
}

\author{
D G R Evans, C Watson, A King, A J Wallace, M E Baser
}

See end of article for

authors' affiliations

J Med Genet 2005;42:45-48. doi: 10.1136/jmg.2004.023705

.......................

Correspondence to: Dr D Gareth R Evans, Department of Medical Genetics, St Mary's Hospital, Hathersage Road, Manchester M13 OJH, UK; gareth.evans@ cmmc.nhs.uk

Revised version received 12 August 2004

Accepted for publication 12 August 2004

\begin{abstract}
Objective: To screen for NF2 mutations in people with meningiomas.
Methods: Lymphocyte or tumour DNA was analysed from 46 individuals from 36 families who presented with a meningioma at age $\leqslant 15$ years without vestibular schwannoma (VS), or who had multiple meningiomas in adulthood before the diagnosis of VS.

Results: Eight of 13 people with meningioma and other features of neurofibromatosis 2 (NF2) had an identified constitutional NF2 mutation in blood DNA, but none of the other subjects had identified constitutional NF2 mutations.

Conclusions: Constitutional NF2 mutations are the most likely cause of meningioma in children and in people with a meningioma plus other non-VS features of NF2. Mosaic NF2 may be the cause of about $8 \%$ of multiple meningiomas in sporadic adult cases, but there are other causes in the majority of other such patients and in multiple meningioma in families.
\end{abstract}

M eningiomas are generally slow growing tumours that are derived from the arachnoid membrane surrounding the central nervous system. They are among the most common intracranial tumours, with an overall incidence of 2.3/100 000 (20\% of all brain tumours) and a $2: 1$ female to male ratio. ${ }^{1}$ About $90 \%$ of meningiomas occur in the cranial meninges and $10 \%$ in the spinal meninges. Asymptomatic meningiomas are often found on computed tomography and magnetic resonance studies, and at necropsy. ${ }^{2}$

Meningiomas commonly occur in neurofibromatosis 2 (NF2). NF2 is an autosomal dominant disorder caused by inactivating mutations of the NF2 tumour suppressor gene. Meningiomas are found in about half the patients with NF2, and sporadic meningiomas often have somatic mutations in the NF2 gene. ${ }^{3-6}$

Apart from NF2, other genes are probably involved in the multistep development of meningiomas. These include those that are presumably inactivated by deletion or mutation in 1p32, a region of frequent loss of heterozygosity ( $\mathrm{LOH})$, in sporadic and hereditary meningiomas. ${ }^{57}$ RAD $54 L$ (OMIM 603615, Locus Link 8438) has been mapped to 1p32 and probably functions in mitotic and meiotic recombination. $R A D 54 \mathrm{~L}$ is a potential candidate gene for meningioma progression but appears to be unrelated to inherited predisposition to meningioma. The $D A L-1$ gene on chromosome 18 is also frequently deleted or mutated in meningiomas. ${ }^{8}$ In one study of multiple meningioma, five of seven patients had non-truncating NF2 mutations in blood-tumour pairs, but these mutations were not considered to be pathogenic. ${ }^{9}$ It is thought that $D A L-1$ is inactivated mainly in those tumours in which NF2 function is already abrogated. ${ }^{10}$

NF2 is often the underlying disease in young people who present with meningioma, ${ }^{11} 12$ but adults with multiple meningiomas and no other signs of NF2 are usually not considered to be at high risk for NF2. In this study, we screened for NF2 mutations in children with meningioma and other features of NF2 except vestibular schwannoma (VS), and in adults with multiple meningiomas but without VS.

\section{METHODS}

Individuals were eligible for the study if they presented with a meningioma at age $\leqslant 15$ years but without VS, or had at least two meningiomas in adulthood but without VS on cranial imaging or at necropsy. In addition, the United Kingdom NF2 registry was searched for individuals who were diagnosed with meningioma at least one year before their diagnosis of VS. Blood samples were obtained with appropriate consent for diagnostic purposes.

Samples were tested for the presence of point mutations by direct sequencing of meta-PCR (polymerase chain reaction) products. ${ }^{13}$ The entire cDNA of the NF2 gene was covered in four meta-PCR reactions. The meta-PCR products were then sequenced in both orientations using BigDye v2 chemistry according to the manufacturer's instructions. Sequencing data were scanned for mutations using the trace subtraction algorithm which is available as a component of the Staden package (www.mrc-lmb.cam.ac.uk/pubseq/). We confirmed identified mutations by repeating the analysis. Dosage analysis was carried out using a quantitative PCR based assay (developed in Manchester) in $10 \mathrm{ml}$ volumes with $100 \mathrm{ng}$ genomic DNA. Gene dosage was measured for four exons of the NF2 gene $(1,4,8$, and 15).

\section{RESULTS}

The patients in tables 1 and 2 are organised into three groups. Patients 1-13 have meningiomas plus other disease features of NF2. Patients 14-17 have multiple meningiomas without other disease features of NF2, but have family members who were diagnosed with NF2 after their own diagnosis of multiple meningioma. Patients 18-50 have multiple meningiomas without other disease features of NF2. Five of these families had more than one affected family member (families 17 and 22-25). In families 22-24, each affected member had spinal meningiomas, while in families 17 and 25, meningiomas were predominantly cranial.

Abbreviations: $\mathrm{LOH}$, loss of heterozygosity; NF2, neurofibromatosis 2; SSCP, single strand conformation polymorphism; VS, vestibular schwannoma 
DNA from blood lymphocytes was available from an affected individual in 33 of the 36 families, but pathogenic constitutional NF2 mutations were not identified in any of these samples. A 26 year old man with multiple meningiomas and his 65 year old clinically unaffected father each had a constitutional $613 \mathrm{G} \rightarrow \mathrm{A}$ missense mutation. A tumour specimen showed $\mathrm{LOH}$ for the other allele, but there was an SSCP shift in tumour that was not present in blood DNA. We were not able to sequence this change owing to insufficient tumour DNA.

Seventeen people had meningiomas plus other disease features of NF2, or a family member with NF2 (patients 1-17). Four of these had a family member who was diagnosed with NF2 after their own diagnosis with multiple meningioma (patients 14-17), and three met the clinical diagnostic criteria for NF2 retrospectively after the diagnosis of NF2 in a child (patients 14-16). In a fourth family (patient 17), a man with three meningiomas had a brother with a single meningioma and a high grade glioma at necropsy. These brothers had a nephew, through an unaffected brother, who had severe NF2 with bilateral VS.

Tumour samples were analysed from patients 9, 16, 17, 23, and 26. NF2 mutations were not identified in patient 16 or in one of the three sisters with spinal meningiomas (patient 23). It was possible to test blood from the children of the two other patients who subsequently met the clinical NF2 diagnostic criteria by having an affected child (patients 14 and 15). A constitutional splice acceptor site mutation (448-1 $\mathrm{G} \rightarrow \mathrm{A}$ ) was identified in the two affected children of patient 15, but a mutation was not identified in the affected child of patient 14. It was possible to test meningioma tissue from patient 17 for the NF2 mutation that was found in his affected nephew. There was no evidence of this mutation in DNA extracted from the paraffin block.

In contrast to the lack of identified constitutional NF2 mutations in these four patients, eight of the 13 individuals with meningioma and other NF2 features had an identifiable constitutional NF2 mutation in blood DNA. Patient 9 had identical $1228 \mathrm{C} \rightarrow \mathrm{T}$ mutations in each of two tumours that were analysed (meningioma and peripheral nerve schwannoma). This suggests that she was mosaic for this mutation, although further analysis of blood DNA did not reveal evidence of the mutation. A constitutional NF2 mutation was not found in a parent-child pair (patients 3 and 4) who had peripheral nerve tumours as well as multiple meningiomas.
In addition to the patients mentioned above, the United Kingdom NF2 registry was searched for NF2 patients who had meningiomas that were identified before the diagnosis of VS. Of the 529 NF2 patients with VS, 34 (6\%) were diagnosed with meningioma at least one year before the diagnosis of VS. If the 16 patients in table 1 who met the clinical diagnostic criteria for NF2 or who had identified constitutional NF2 mutations (patients 1-16) are added to these 34 patients, about $8 \%$ of NF2 patients present with meningioma before developing VS.

\section{DISCUSSION}

In published reports, multiple meningiomas are most often described in association with NF2. An epidemiological study in Finland suggested that as few as $20 \%$ of patients with multiple meningiomas had NF2. ${ }^{14}$ This is probably an underestimate because the estimated birth incidence of NF2 was only 1 in 87410 , compared with 1 in 33-40 000 in a larger study in the United Kingdom. ${ }^{15}$ Also, it is well known that some people who present only with meningiomas develop classical NF2.

In this study, we found that about $8 \%$ of NF2 patients present with meningioma before a VS. We previously reported that at least $20 \%$ of children who present with a meningioma developed NF2. ${ }^{11}$ In the present study, seven of nine children with meningioma and other features of NF2, but no family history of NF2, had an identifiable constitutional NF2 mutation. However, three children who presented with multiple meningiomas alone did not have an identifiable constitutional NF2 mutation. Nonetheless, all children with a meningioma should be considered to be at risk for NF2 and have follow up imaging of the cranium and constitutional NF2 mutation analysis.

The situation in adults with multiple meningiomas is more complex. In this study, constitutional NF2 mutations were not identified in any adults who had multiple meningiomas but no other features of NF2. However, three of 36 adults with multiple meningiomas had a child who developed NF2 after their parent's diagnosis of meningioma.

Only one of these three adults was alive, and a pathogenic NF2 mutation in lymphocyte DNA could not be identified, but he must have been at least mosaic in the gonads and neural crest because both of his daughters had identified constitutional NF2 mutations. Another patient was a proven NF2 mosaic. Taken together, these results indicate that at

Table 1 Children with multiple meningiomas and other NF2 features or a family history of NF2

\begin{tabular}{|c|c|c|c|c|c|c|c|}
\hline Pt & Sex & $\begin{array}{l}\text { Age at Dx/last } \\
\text { exam (years) }\end{array}$ & $\begin{array}{l}\text { Number and location } \\
\text { of meningiomas }\end{array}$ & $\begin{array}{l}\text { Presenting } \\
\text { symptom }\end{array}$ & Other NF2 features & $\begin{array}{l}\text { Family } \\
\text { history }\end{array}$ & Mutation \\
\hline 1 & M & $9 / 9$ & 1 cranial & Visual loss & Trigeminal schwannoma & None & Not found \\
\hline 2 & M & $7 / 9$ & 1 cranial & Visual loss & $\begin{array}{l}4 \text { cutaneous tumours and } \\
\text { hypoglossal schwannoma }\end{array}$ & None & Not found \\
\hline $4^{*}$ & M & $9 / 16+$ & 4 cranial & Seizures & 4 cutaneous tumours & $\begin{array}{l}\text { Mother } \\
\text { (patient 3) }\end{array}$ & Not found \\
\hline 6 & M & $2 / 6+$ & 3 cranial & Visual loss & Trigeminal schwannoma (bilateral) & None & Not found \\
\hline 7 & M & $5 / 8$ & 2 cranial & Visual loss & $\begin{array}{l}2 \text { spinal and } 3 \text { cutaneous } \\
\text { schwannomas }\end{array}$ & None & $887 \mathrm{del} \mathrm{T}$ \\
\hline 8 & M & $9 / 10$ & 1 cranial & Seizures & 3 spinal tumours & None & 58 ins $A$ \\
\hline 10 & M & $7 / 9$ & 2 cranial & Seizures & Cataract & None & $592 \mathrm{C}>\mathrm{T}$ \\
\hline 12 & M & $4 / 4$ & 1 cranial & Visual loss & $\begin{array}{l}\text { 3rd nerve palsy and } 3 \\
\text { cutaneous schwannomas }\end{array}$ & None & $241-2 \mathrm{G}>\mathrm{A}$ \\
\hline 13 & M & $7 / 8$ & 1 cranial & Facial palsy & Facial palsy & None & 443 del C \\
\hline 19 & M & 10 & 2 cranial & NA & NA & None & Not found \\
\hline 20 & M & 15 & $\begin{array}{l}\text { 2: optic sheath } \\
\text { and falx }\end{array}$ & NA & NA & None & Not found \\
\hline 21 & M & $13 / 33$ & 2 cranial & NA & None & None & Not found \\
\hline
\end{tabular}

*Deceased.

tFamily history in first degree relative of multiple meningiomas.

Patients 1-13 have meningioma(s) plus other disease features of NF2. Patients 19-21 have multiple meningiomas without other disease features of NF2.

Dx, diagnosis; exam, examination; F, female; M, male; NA, data not available; NF2, neurofibromatosis 2; pt, patient. 


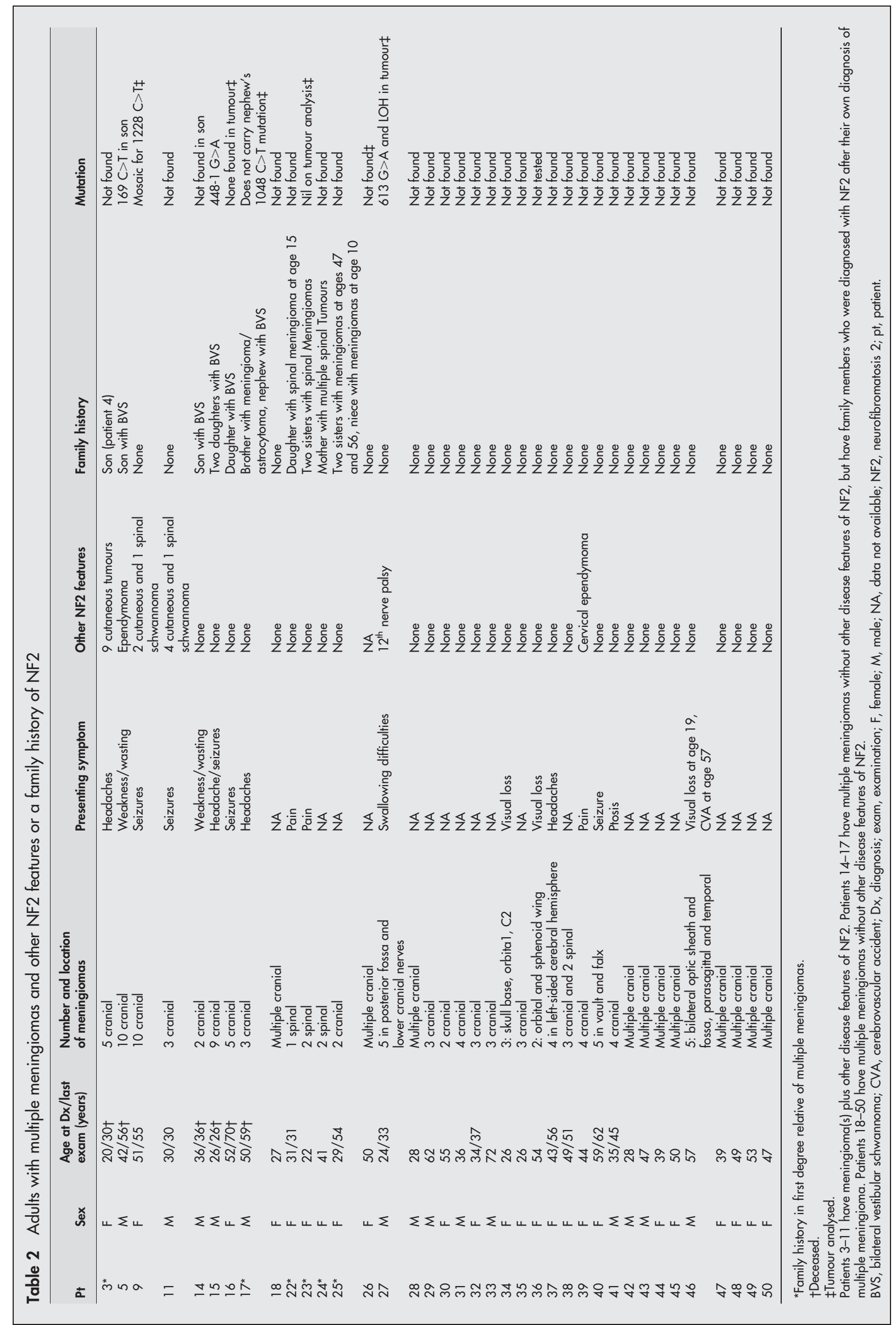


least some adults with multiple meningiomas but without VS are mosaic for an NF2 mutation. ${ }^{16}{ }^{17}$ The occurrence of meningioma in two uncles of a person with NF2 is almost certainly a coincidence because the intervening male relative died at age 68 without features of NF2 (which is very unlikely if he had the same NF2 truncating mutation) and the two uncles did not have VS at necropsy.

Analysis of lymphocyte DNA often misses mosaicism. ${ }^{16}{ }^{18}$ Consideration should be given to analysing tumour specimens, particularly if more than one tumour is being removed. The presence of an identical NF2 mutation in more than one tumour is indicative of mosaicism. Absence of the family NF2 mutation in blood samples from children would rule out NF2, although there may still be a small risk of meningioma. This risk is due to the known monoclonal pattern of involvement in some multiple meningioma patients ${ }^{18}$ and the occurrence of true meningioma families. A study of seven families with multiple meningiomas found two isolated patients who had the same NF2 mutation in multiply sampled meningiomas, and it was unclear if this represented mosaicism or clonal spread across the meninges. . Patient 9 in the present study is clearly mosaic because the second tumour analysed was a schwannoma.

Somatic NF2 mosaicism is the probable cause of multiple meningiomas in some individual adults, but there are other genetic causes in the majority of such adults and in probably all the reported multiple meningioma families. The NF2 locus has essentially been excluded by protein analysis in some multiple meningioma families ${ }^{19}$; no such families have been reported with constitutional NF2 mutations, ${ }^{20}$ and linkage analysis excluded the NF2 locus in one family with multiple meningiomas and ependymomas. ${ }^{21}$ Similarly, the results of tumour mutation analysis do not implicate the NF2 locus in most individual multiple meningioma patients. ${ }^{20}$ Some isolated meningiomas can be caused by radiotherapy, ${ }^{22}$ and a previous history of radiation treatment should always be elicited.

A polymorphic marker in the $R A D 54 L$ gene on lp has been implicated as a risk factor for meningioma, but it is probably not sufficient to cause multiple tumours. ${ }^{23}$ Tumour pathology is useful because meningiomatous meningiomas are almost never NF2 related $^{24}$ and skull base tumours are also rare. ${ }^{25}$ Unfortunately, details on the pathology of the meningiomas in our study were not complete.

This is the largest series of multiple meningioma patients reported to date. Heritable and non-heritable meningiomas differ with respect to haploinsufficiency in surrounding tissues and mutational spectra. Constitutional NF2 mutations are the most likely cause of meningioma in children and in individuals with a meningioma plus other non-VS features of NF2. Mosaic NF2 may be the cause of about $8 \%$ of multiple meningiomas in individual adult patients, but there are other causes in the majority of such adults and in multiple meningioma families.

\section{Authors' affiliations}

D G R Evans, C Watson, A J Wallace, Academic Unit of Department of Medical Genetics, National Genetics Reference Laboratory and Regional Genetics Service, St Mary's Hospital, Manchester, UK

A King, Department of Neurosurgery, Hope Hospital, Manchester

M E Baser, Los Angeles, California, USA

Competing interests: none declared

\section{REFERENCES}

1 Bondy M, Lignon BL. Epidemiology and etiology of intracranial meningiomas: a review. J Neurooncol 1996;29:197-205.

2 Kuratsu J, Kochi M, Ushio Y. Incidence and clinical features of asymptomatic meningiomas. J Neurosurg 2000;92:766-70.

3 Evans DGR, Huson SM, Donnai D, Neary W, Blair V, Newton V, Harris R. A clinical study of type 2 neurofibromatosis. Q J Med 1992;84:603-18.

4 Harada T, Irving RM, Xuereb JH, Barton DE, Hardy DG, Moffat DA, Maher ER. Molecular genetic investigation of the neurofibromatosis type 2 tumor suppressor gene in sporadic meningioma. J Neurosurg 1996;84:847-51.

5 Lamszus K, Vahldiek F, Mautner VF, Schichor C, Tonn J, Stavron D Fillbrandt R, Westphal M, Kluwe L. Allelic losses in neurofibromatosis 2associated meningiomas. J Neuropathol Exp Neurol 2000;59:504-12.

6 Leone PE, Bello MJ, de Campos JM, Vaquero J, Sarasa JL, Pestaña A, Rey JA. NF2 mutations and allelic status of $1 p, 14 q$ and $22 q$ in sporadic meningiomas. Oncogene 1999;18:2231-9.

7 Sulman EP, Dumanski JP, White PS, Khao H, Maris JM, Mathiesen T, Bruder C, Cnaan A, Brodeur GM. Identification of a consistent region of allelic loss on 1 p32 in meningiomas: correlation with increased morbidity. Cancer Res 1998; 58:3226-30.

8 Gutmann DH, Donahoe J, Perry A, Lemke N, Gorse K, Kittiniyom K Rempel SA, Gutierrez JA, Newsham IF. Loss of DAL-1, a protein 4.1-related tumor suppressor, is an important early event in the pathogenesis of meningiomas. Hum Mol Genet 2000;9:1495-500.

9 Heinrich B, Hartmann C, Stemmer-Rachamimov AO, Louis DN, MacCollin M. Multiple meningiomas: investigating the molecular basis of sporadic and familial forms. Int J Cancer 2003;103:483-8.

10 Perry A, Cai DX, Scheithauer BW, Swanson PE, Lohse CM, Newsham IF, Weaver A, Gutmann DH. Merlin, DAL-1, and progesterone receptor expression in clinicopathologic subsets of meningioma: a correlative immunohistochemical study of 175 cases. J Neuropathol Exp Neurol 2000;59:872-9.

11 Evans DGR, Ramsden R, Birch J. Paediatric presentation of type 2 neurofibromatosis. Arch Dis Child 1999:81:496-9.

12 Perry A, Giannini C, Raghavan R, Scheithaver BW, Banerjee R, Margraf L, Bowers DC, Lytle RA, Newsham IF, Gutmann DH. Aggressive phenotypic and genotypic features in pediatric and NF2-associated meningiomas: a clinicopathologic study of 53 cases. J Neuropathol Exp Neurol 2001;60:994-1003.

13 Wallace AJ, Wu C-L, Elles RG. Meta-PCR: a novel method for creating chimaeric DNA molecules and increasing the productivity of mutation screening techniques. Genetic Testing 1999;3:173-83.

14 Antinheimo J, Sankila R, Carpen O, Pukkala E, Sainio M, Jaaskelainen J. Population-based analysis of sporadic and type 2 neurofibromatosisassociated meningiomas and schwannomas. Neurology 2000:54:71-6.

15 Evans DGR, Huson SM, Donnai D, Neary W, Blair V, Teare D, Newton V, Strachan T, Ramsden R, Harris R. A genetic study of type 2 neurofibromatosis in the north west of England and the UK: I. Prevalence, mutation rate, fitness and confirmation of maternal transmission effect on severity. J Med Genet 1992:29:841-6.

16 Moyhuddin A, Baser ME, Watson C, Purcell S, Ramsden RT, Heiberg A, Wallace AJ, Evans DGR. Somatic mosaicism in neurofibromatosis 2: prevalence and risk of disease transmission to offspring. J Med Genet 2003;40:459-63.

17 Zhu JJ, Maruyama T, Jacoby LB, Herman JG, Gusella JF, Black PM, Wu JK. Clonal analysis of a case of multiple meningiomas using multiple molecular genetic approaches: pathology case report. Neurosurgery 1999;45:409-16.

18 Evans DGR, Wallace A, Trueman L, Wu C-L, Ramsden RT, Strachan T. Mosaicism in classical neurofibromatosis type 2: a common mechanism for sporadic disease in tumor prone syndromes? Am J Hum Genet 1998;63:727-36

19 Maxwell M, Shih SD, Galanopoulos T, Hedley-Whyłe ET, Cosgrove GR. Familial meningioma: analysis of expression of neurofibromatosis 2 protein Merlin. Report of two cases. J Neurosurg 1998;88:562-9.

20 Lomas J, Bello MJ, Alonso ME, Gonzalez-Gomez P, Arjona D, Kusak ME, de Campos JM, Sarasa JL, Rey JA. Loss of chromosome 22 and absence of NF2 gene mutation in a case of multiple meningiomas. Hum Pathol 2002;33:375-8.

21 Pulst SM, Rouleau GA, Marineau C, Fain P, Sieb JP. Familial meningioma is not allelic to neurofibromatosis 2. Neurology 1993;43:2096-8.

22 Sadetzki S, Flint-Richter P, Ben-Tal T, Nass D. Radiation-induced meningioma: a descriptive study of 253 cases. J Neurosurg 2002;97:1078-82.

23 Evans JJ, Jeun SS, Lee JH, Harwalkar JA, Shoshan Y, Cowell JK, Golubic M. Molecular alterations in the neurofibromatosis type 2 gene and its protein rarely occurring in meningothelial meningiomas. J Neurosurg 2001;94:111-17.

24 Kros J, de Greve K, van Tilborg A, Hop W, Pieterman H, Avezaat C, LekanneDeprez R, Zwarthoff E. NF2 status of meningiomas is associated with tumour localization and histology. J Pathol 2001;194:367-72.

25 Leone PE, Mendiola M, Alonso J, Paz-y-Mino C, Pestana A. Implications of a RAD54L polymorphism (2290C/T) in human meningiomas as a risk factor and/or a genetic marker. BMC Cancer 2003;3:6. 